\title{
\#Me Too Movement; It Is Time That We All Act and Participate in Transformation
}

\author{
Bun-Hee Lee \\ Maum \& Maum Psychiatric Clinic, Seoul, Republic of Korea
}

Human rights and equality have progressed and matured slowly. In the progress, we had gained the civil and female suffrage. Moreover, another transformation recently springs up around the world. That is the Me Too movement.

The Me Too movement (or \#Me Too) is a movement against sexual harassment and assault. ${ }^{1}$ \#MeToo spread on social media in October 2017, and then it revealed the prevalence and magnitude of problems with sexual harassment and assault, especially in the workplace, including academia and medicine. Research showed that about $30 \%$ of women and $4 \%$ of men among U.S. academic medical faculty members reported experiencing sexual harassment. ${ }^{2}$ Other reported that $60 \%$ of medical trainees and students experienced harassment or discrimination during training. ${ }^{3}$ Moreover, this movement has led widespread discussion about how to stop problems with sexual abuse or harassment at work. The world no longer considers these issues to be solved by individuals.

There have been some barriers among these discussions or debates which should be overcome in the future. One of them is a vigilance movement to keep a distance from other gender. For example, some men have expressed the desire to keep a greater distance from women. Perhaps such a reaction is because they do not fully understand what actions is considered inappropriate or wrong. And it is more worrying that those responses seem to be reactive aggression behind it. Such a confrontation between genders does not help solve the problem with sexual harassment and assault in the workplace. Other is a wrong prejudice; when the problem with sexual harassment is accused, it is sometimes regarded as an accuser's fault or evidence of social maladjustment. This misguided prejudice and atmosphere have kept victims in silence for a long time. Therefore, this wrong prejudice should be elimi-

\footnotetext{
$\triangle$ Correspondence: Bun-Hee Lee, MD, PhD

Maum \& Maum Psychiatric Clinic, 399 Gosanja-ro, Dongdaemun-gu, Seoul 02566, Republic of Korea

Tel: +82-2-69590456, Fax: +82-31-69590457, E-mail: lee.bunhee@gmail.com

(a) This is an Open Access article distributed under the terms of the Creative Commons Attribution Non-Commercial License (http://creativecommons.org/licenses/by$\mathrm{nc} / 4.0$ ) which permits unrestricted non-commercial use, distribution, and reproduction in any medium, provided the original work is properly cited.
}

nated.

It was suggested that the \#Me Too movement has shifted the norms surrounding sexual harassment in workplaces. One of them is the agreement that sexual harassment (not just sexual assault) constitutes a threat and is unacceptable in the workplace. ${ }^{4}$

It requires policies, education, and training to accomplish these shifts of the norm. Policies must include an effective reporting and investigation system. Because there is a general consensus that a lack of effective reporting systems is a major factor that drives sexual misconduct in the workplace. Some organizations have set up an independent intermediary or outside system or options with a hotline to report inappropriate actions. And it needs to develop public policies and systems to provide protection and support services for legal and psychological issues. Above all, education and training are more important and necessary. The contents of the education and training should include as the followings: what words and behaviors are sexual harassment or gender bias, and when she or he experiences or observes sexual harassment or gender bias, she or he can speak up without fear and should be encouraged to do.

This recent transformation is not limited to sexual harassment and assault, but it should be expanded as follows: Discrimination or harassment based on gender, race, color, religion, national origin, gender orientation, gender identity, age, or disability will not be tolerated in anyone. We all have to act and participate to achieve the shift and change.

\section{REFERENCES}

1. Zacharek S, Dockterman E, Edwards HS. The silence breakers. TIME. Available at: http://time.com/time-person-of-the-year-2017-silencebreakers. Accessed March 20, 2018.

2. Isaacs D. Sexual harassment. J Paediatr Child Health 2018;54:341-342.

3. Launer J. Sexual harassment of women in medicine: a problem for men to address. Postgrad Med J 2018;94:129-130.

4. Drezner DW. \#MeToo and the trouble with new norms. Washington Post. Available at: https://www.washingtonpost.com/news/posteverything/wp/2018/02/14/metoo-and-the-trouble-with-norms. Accessed February 20, 2018. 